\title{
Supplement of levosimendan to epinephrine improves initial resuscitation outcomes from asphyxial cardiac arrest
}

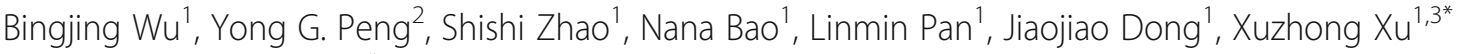 \\ and Quanguang Wang ${ }^{1, *^{*}}$
}

\begin{abstract}
Background: Levosimendan exerted favorable effects on the initial outcome in the treatment of ventricular fibrillation cardiac arrest. This study investigated the efficacy of levosimendan in the treatment of asphyxiainduced cardiac arrest in rats.

Methods: Animals underwent asphyxial cardiac arrest/cardiopulmonary resuscitation, randomized to three treatment groups: epinephrine (10 $\mu \mathrm{g} / \mathrm{kg}$ ) supplemented with levosimendan (bolus $12 \mu \mathrm{g} / \mathrm{kg}$ and infusion for $1 \mathrm{~h}$, EL group); epinephrine only (10 $\mu \mathrm{g} / \mathrm{kg}$, E group), or levosimendan only (bolus $12 \mu \mathrm{g} / \mathrm{kg}$ and infusion for $1 \mathrm{~h}$, $L$ group). The resuscitation success rate, wet-to-dry ratio of lung, and rate of alveolar and blood gas analysis were recorded.

Results: 10 rats in the EL group, 8 in the E group, and 2 in the $L$ group showed an initial return of spontaneous circulation $(P<0.001)$; among them, 10, 4, and 2 rats survived at the end of a 60 -min observation period from each group, respectively $(P=0.001)$. The coronary perfusion pressure in the EL group was higher than that of either the $\mathrm{E}$ or $\mathrm{L}$ group $(P<0.05)$. The lung wet-to-dry weight ratio and rate of damaged alveoli were lower in the $\mathrm{EL}$ group than the $\mathrm{E}$ group $(P<0.05)$.

Conclusions: In the early stage of resuscitation for asphyxia-induced cardiac arrest in rats, levosimendan supplemented with epinephrine can significantly increase coronary perfusion pressure, reduce lung injury, and ultimately enhance the survival rate.
\end{abstract}

Keywords: Asphyxia, Cardiac arrest, Epinephrine, Levosimendan, CPR

\section{Background}

Cardiac arrest (CA) is the most devastating adverse cardiac event, and it causes approximately 325,000 deaths each year in the United States [1]. Asphyxia, a result from loss of the airway, is a rare but significant cause of serious complications, and can lead to an asphyxiainduced CA. Epinephrine is a standard of medication in resuscitation of $\mathrm{CA}$ and it has been incorporated into the American Heart Association guidelines for cardiopulmonary resuscitation since 1973. It exhibits potent vasoconstriction effect, increases coronary perfusion

\footnotetext{
* Correspondence: xuzhong@263.net; quanguangwang@sina.com 'Department of Anesthesiology, The First Affiliated Hospital, Wenzhou Medical University, Wenzhou City, Zhejiang Province, China

Full list of author information is available at the end of the article
}

pressure (CPP), and facilitates return of spontaneous circulation (ROSC) $[2,3]$ However, the effects of sole epinephrine in the setting of CA have always been questioned because it increases myocardial oxygen demand through its beta adrenergic receptors [4], which cause post-resuscitation myocardial dysfunction [5]. It also exerts acute, adverse effects on pulmonary oxygen exchange, which then leads to severe pulmonary edema and acidosis [6]. These unwarranted side effects have a negative impact on long-term survival. Therefore, the American Heart Association guidelines have now discouraged large doses of epinephrine for adult advanced cardiovascular life support during resuscitation [7]. In clinical practice, however, epinephrine is still the preferred agent during cardiopulmonary resuscitation (CPR). 
Levosimendan is a unique inodilator that exerts inotropic effects principally via binding to the $\mathrm{Ca}^{2+}$-saturated troponin $\mathrm{C}$ of the myocardial thin filament [8]. Unlike classic inotropic agents, it has inotropic action without increasing myocardial oxygen consumption during infusion in congestive heart failure [9]. Furthermore, levosimendan also has vasodilatory effects mediated by the opening of ATP-sensitive potassium channels in the sarcolemmal membrane of vascular smooth muscle cells [10], which decreases the central venous pressure and the systolic and diastolic pressures of the right atrium [11].

There are conflicting reports in the literature regarding the efficacy of levosimendan in the treatment of CA. Kelm et al. [12] reported that levosimendan combined with vasopressin administration during $\mathrm{CPR}$ resulted in increased cerebral blood flow and improved neurological outcome, but could not facilitate ROSC in a rat model of asphyctic CA. The recent research reported by Kosmidou et al. [13] showed that levosimendan combined with epinephrine only improved 24-h neurological outcome, but there was no evidence of improvement of initial resuscitation success and the final survival rate in a swine model of asphyctic CA. However, Koudouna et al. [14] reported that a combination of epinephrine and levosimendan in a swine model of ventricular fibrillation CA significantly improved CPP and initial resuscitation success. Thus, it is not clear whether levosimendan could play a beneficial role in the process of resuscitation; additional studies are necessary for providing further evidence to confirm the benefit of levosimendan during resuscitation with different animal CA models.

We hypothesized that levosimendan combined with epinephrine can improve post-resuscitation outcomes and survival rates in the treatment of asphyxia-induced $\mathrm{CA}$, and designed a double-blind, prospective, randomized study using a rat model after asphyctic CA. The primary end point assessed was the survival rate, and the secondary end points were the rate of ROSC, the lung wet-to-dry weight ratio, and hemodynamic parameters.

\section{Methods}

\section{Experimental animals and groups}

All studies were approved by the Ethics Committee of the Wenzhou Medical University (Wenzhou, China). Healthy Sprague-Dawley male rats, 7 to 8 weeks old, 300 to 350 gin weight, were divided randomly into three experimental groups (10rats/group) randomly: the epinephrine (Jinyao Amino Acid Co., Ltd., Tianjin, China) and levosimendan (Qilu pharmaceutical Co., Ltd., Shandong, China) treatment group (EL), the epinephrine (10 $\mu \mathrm{g} / \mathrm{kg}$ in $2.5 \mathrm{ml}$ of volume) combined with levosimendan [bolus during CPR $(12 \mu \mathrm{g} / \mathrm{kg}$ in $1.2 \mathrm{ml}$ of volume) and infusion for $1 \mathrm{~h}(0.3 \mu \mathrm{g} / \mathrm{kg} / \mathrm{min}$ in $0.03 \mathrm{ml}$ of volume)], and the epinephrine-only treatment group (E), epinephrine $(10 \mu \mathrm{g} / \mathrm{kg}$ in $2.5 \mathrm{ml}$ of volume $)$ administered with saline $0.9 \%$ [bolus during CPR and infusion for $1 \mathrm{~h}$ (equivalent fluid volume)] or levosimendan-only treatment group (L), saline $0.9 \%$ (equivalent fluid volume bolus) administered with levosimendan [bolus $12 \mu \mathrm{g} / \mathrm{kg}$ in $1.2 \mathrm{ml}$ of volume and infusion for $1 \mathrm{~h}(0.3 \mu \mathrm{g} / \mathrm{kg} / \mathrm{min}$ in $0.03 \mathrm{ml}$ of volume)].

\section{Animal preparation}

All rats were fasted for $12 \mathrm{~h}$ before the experiment began and were given access to water ad libitum. They were anesthetized with an intraperitoneal injection of urethane $(20 \%, 200 \mathrm{mg} / \mathrm{kg})$. A tracheal intubation was performed via tracheotomy and rats were connected to the rodent volume-controlled ventilator (tidal volume, $8 \mathrm{ml} / \mathrm{kg} ; \mathrm{FiO}_{2}, 1.0$; respiratory rate, $75-80$ breaths/min; inspiratory/expiratory ratio, 2:3; HX-300; TME Technology Co., Ltd., Chengdu, China) $[15,16]$. The right femoral artery was cannulated for the sampling of blood and continuous arterial pressure monitoring. Intravenous drug administration took place through drug right femoral vein cannulation. A third catheter was inserted into the left jugular vein and then advanced into the right atrium for measuring the right atrial pressure. Electrocardiography, using three subcutaneous needle electrodes, continuously recorded arterial and right atrial pressure throughout the duration of the experiments with a MedLab data archiving and retrieval system using U/4C051 (Nanjing Medease Science and Technology Co., Ltd., Jiangsu, China). All animals were stabilized for 15 min after completion of invasive procedures. Thereafter, CPP, mean arterial pressure (MAP), heart rate $(\mathrm{HR})$, and rate-pressure product (RPP) were recorded. CPP was calculated as the difference between decompression diastolic aortic and time-coincident right atrial pressure and was measured at the end of each minute of precordial compression [14]. Arterial blood gases (ABGs) were also collected [17].

\section{Experimental model}

The asphyxia-induced CA model was quoted from the experiment performed by McCaul et al. [18]. After a stabilization periodof $15 \mathrm{~min}$, CA was achieved by stopping mechanical ventilation, which resulted in CA after approximately $3 \mathrm{~min}$. CA was indicated by a decrease in MAP below $10 \mathrm{mmHg}$. All rats in each group were led to CA.

\section{Resuscitation protocol}

Resuscitation began $1 \mathrm{~min}$ after onset of $\mathrm{CA}$ and was established by starting the ventilator $\left(\mathrm{FiO}_{2} 1.0, \mathrm{~V}_{\mathrm{T}} 8 \mathrm{ml} /\right.$ $\mathrm{kg}$, rate $75-80 \mathrm{~min}^{-1}$ ), beginning external chest compressions (approximately $300 \mathrm{~min}^{-1}$ at a depth of $1 \mathrm{~cm}$ ), and through intravenous administration of medication. 
Effective resuscitation (ROSC) was defined as a native RPP more than $20 \%$ of baseline value for 1 min $[15,19]$. Chest compressions continued until spontaneous circulation returned or an elapsed time of $60 \mathrm{~min}$ without successful resuscitation; no ventilation changes were made before or after resuscitation. We used an adjustable infrared sensor maintain body temperature at $37{ }^{\circ} \mathrm{C}$ to $39{ }^{\circ} \mathrm{C}$, and we preheated all intravenous solutions to $37{ }^{\circ} \mathrm{C}$ before infusion. At the end of the 60 -min resuscitation period, the animals were killed by anesthetic overdose, and the excised lung samples were taken for subsequent analysis.

\section{Measurements}

We dynamically documented the values of SBP, MAP, and HR in all three groups and calculated the RPP and CPP of the survivors during the 60 -min resuscitation period. In addition, we recorded the time to $\mathrm{CA}$, the time to first heartbeat, and the time to ROSC. ROSC and rats surviving at $60 \mathrm{~min}$ were also recorded. The rate of successful resuscitation and survival at $60 \mathrm{~min}$ was calculated (rate of ROSC = number of rats displaying ROSC/total number of rats; survival at $60 \mathrm{~min}=$ number of rats survived at $60 \mathrm{~min} /$ total number of rats). Finally, arterial blood gas analyses were performed.

\section{The wet-to-dry ratio of the lung and pathology}

The animals were sacrificed after CPR. The lobe of the left lung was weighed and dried, and we calculated the lung wet-to-dry weight ratio. We fixed the middle lobe of the right lungin $10 \%$ formalin fixative, created paraffinembedded slices, and used hematoxylin and eosin stain for observation [15]. Fifty views (400x) were selected randomly in each sample by using light microscopy. In every view, the total number of pulmonary alveoli and the number damaged were counted. We then calculated the ratio of damaged lung alveoli to the total number of lung alveoli. We defined the alveolus as injured when more than two inflammatory cells or two red blood cells were evident in one pulmonary alveolus $[15,20]$.

\section{Statistical analysis}

Based on our pre-test, we used the Power Sample Size (PASS11.0) software program for power analysis and compared the survival rates among the experimental groups. In our preliminary study, 18 rats were used, with 6 rats in each group. There were 6, 1, and 1 rat in groups EL, E, and $\mathrm{L}$ that survived to $60 \mathrm{~min}$, respectively. The survival rate was $100,16.7$, and $16.7 \%$, respectively. We set the power at 0.8 ; the significance criterion was 0.017 . As a result, we needed 8 rats per group to achieve statistical significance. To account for potential attrition, we enrolled 10 rats per group.
All data were performed using SPSS for 17.0 for Windows. All data generated or analysed during this study are included in this published article (Additional file 1). The measurement data were presented as means \pm standard deviation (SD), and in the case of categorical variables, frequencies were used. We used the ShapiroWilk test to analyze normal distribution. Differences of baseline parameters, time to CA, time to first heartbeat, time to ROSC, blood gas parameters, lung wet-to-dry ratio, and the ratio of damaged alveoli in the three groups were compared by one-way analysis of variance. We used the least significant difference test for the data that had homogeneity of variance, and the Dunnett's T3 test was used for the data that exhibited heterogeneity of variance. Differences of hemodynamic parameters in animals were analyzed by two-way, repeated-measures analysis of variance, and Bonferroni post hoc analysis when significance was achieved. $P$ value $<0.05$ was considered significant. Fisher probabilities in a $3 \times 2$ table were used for analyzing success resuscitation rates and survival rates, and $P$ value $<0.017$ was considered significant in post hoc multiple comparisons.

\section{Results}

\section{Baseline values}

There were no differences observed in weight, baseline hemodynamic metrics, or baseline blood gas values among the groups (Table 1).

\section{Resuscitation outcomes}

All animas in each group experienced CA for approximately $3 \mathrm{~min}$, and no significant difference was found among the three groups in the time to CA $(P=0.986$; Table 2). The numbers of animals with ROSC in the EL, E, and L groups were 10, 8, and 2, respectively; the three groups displayed different ROSC rates (10 rats in each group; $P<0.001$; Table 2). The numbers of animals surviving to 60 min were 10,4 , and 2 , in the EL, E, and $\mathrm{L}$ groups, respectively. The EL, E, and L groups thus displayed a difference in rates of survival $(P=0.001$; Table 2). The groups also demonstrated differences in the time to return of pulse $(P<0.001$; Table 2$)$ and the time to $\operatorname{ROSC}(P=0.001$; Table 2$)$. The time to ROSC of the survived rats, and its distribution in the three groups, is presented in Fig. 1.

\section{Hemodynamic measures}

Hemodynamic values such as CPP, MAP, HR, and RPP for the three groups are presented in Fig. 2. Significant differences were seen in CPP, MAP, HR, and RPP among the EL, E, and L groups $(P<0.05)$. Further comparisons in the first $3 \mathrm{~min}$, e.g., the CPP and MAP, but not the $\mathrm{RPP}$ or HR, in the EL group were higher than that in the E or L group $(P<0.05)$. 
Table 1 Baseline Values of Weight, Hemodynamic Metrics, and Blood Gas Values for group EL, group E and group L

\begin{tabular}{lllll}
\hline & EL group $(n=10)$ & E group $(n=10)$ & L group $(n=10)$ & $P$ value \\
\hline Weight, g & $320 \pm 16$ & $326 \pm 12$ & $332 \pm 13$ & 0.174 \\
$\mathrm{SBP}, \mathrm{mmHg}$ & $113 \pm 11$ & $108 \pm 7$ & $114 \pm 9$ & 0.310 \\
$\mathrm{RPP}, \mathrm{mmHg} \cdot$ beat $\cdot \mathrm{min}^{-1}$ & $50886 \pm 6330$ & $47889 \pm 3750$ & $47997 \pm 5075$ & 0.352 \\
$\mathrm{CPP}, \mathrm{mmHg}$ & $72 \pm 10$ & $69 \pm 9$ & $73 \pm 7$ & 0.695 \\
$\mathrm{PH}$ & $7.39 \pm 0.03$ & $7.39 \pm 0.04$ & $7.37 \pm 0.04$ & 0.248 \\
$\mathrm{PaO}_{2}, \mathrm{mmHg}$ & $369 \pm 32$ & $355 \pm 40$ & $389 \pm 62$ & 0.290 \\
$\mathrm{HCO}_{3}^{-}, \mathrm{mmol} / \mathrm{L}$ & $22.6 \pm 2.6$ & $22.2 \pm 2.3$ & $24.2 \pm 2.4$ & 0.176 \\
$\mathrm{BE}, \mathrm{mmol} / \mathrm{L}$ & $-2.3 \pm 3.1$ & $-2.7 \pm 2.1$ & $-1.5 \pm 2.1$ & 0.550 \\
Lactate, $\mathrm{mmol} / \mathrm{L}$ & $1.1 \pm 0.5$ & $1.2 \pm 0.4$ & $1.5 \pm 0.3$ & 0.074 \\
\hline
\end{tabular}

Normally distributed data were given as mean \pm SD. No statistical difference among the 3 groups. SBP indicates systolic blood pressure. RPP indicates rate-pressure product (systolic blood pressure $\times$ heart rate). CPP indicates coronary perfusion pressure. BE indicates base excess

\section{Lung wet-to-dry weight ratio}

The EL, E, and L groups showed differences in lung wetto-dry weight ratios $(5.1 \pm 0.3,6.0 \pm 0.4$, and $5.7 \pm 0.6$, respectively; $P=0.005)$. The ratio in the EL group was significantly lower than that of the E group ( $P=0.001$; Fig. 3$)$.

\section{Lung histological examination}

In the EL group, there was no evidence of alveolar structural damage, edema, or hemorrhage. In the E group, there were numerous erythrocytes in the alveolar field, accompanied by altered alveolar structures. In the $\mathrm{L}$ group, some alveoli could be identified, and there were numerous erythrocytes observed in the injured alveoli (Fig. 4). The EL, E, and L groups showed differences in the rate of injured alveoli $(0.15 \pm 0.07,0.74 \pm 0.08,0.53 \pm$ 0.31 , respectively; $P=0.002$ ). The rate of damaged alveoli in the EL group was significantly lower than that of the E group $(P<0.001)$.

\section{Blood gas analysis}

Arterial blood gas parameters at $60 \mathrm{~min}$ are shown in Table 3. The EL, E, and L groups displayed significant differences in blood gas parameters $(P<0.05)$. Specifically, the $\mathrm{PH}, \mathrm{PaO}_{2}, \mathrm{HCO}_{3}^{-}$and base excess $(\mathrm{BE})$ values of the EL group were significantly higher than that of the $\mathrm{E}$ group (PH: EL vs. E, $P=0.021 ; \mathrm{PaO}_{2}$ : EL vs. $\mathrm{E}, P<0.001$; $\mathrm{HCO}_{3}^{-}$: EL vs. E, $P=0.004$; $\mathrm{BE}$ : EL vs. $\left.\mathrm{E}, P=0.004\right)$. In addition, the $\mathrm{PH}$ values and $\mathrm{BE}$ in the $\mathrm{EL}$ group were significantly higher than that of the L group (PH: EL vs. L, $P=0.024 ; B E$ : EL vs. L, $P=0.01$ ). The blood lactate value in the EL group was significantly lower than that of the $\mathrm{E}$ or $\mathrm{L}$ group (EL vs. E, $P=0.018$, EL vs. L, $P=0.001$; Table 3).

\section{Discussion}

In our study of resuscitation on asphyxia-induced CA, we demonstrated that CPP significantly improves when rats received epinephrine therapy supplemented with levosimendan. The EL group also exhibited a significant reduction in lung injury and acidosis, excellent oxygen partial pressure, and an improved survival rate compared with rats that received epinephrine or levosimendan alone.

CPP, calculated as aortic pressure minus right atrial pressure during the diastolic phase of CPR, is strongly associated with resuscitation outcomes $[17,21]$. Friess et al. reported that maintaining $\mathrm{CPP}>20 \mathrm{mmHg}$ is the primary determinant for ROSC and survival from CA [22]. Levosimendan can decrease the central venous pressure and the systolic and diastolic pressures of the right

Table 2 Resuscitation Outcomes for EL, E and L Groups

\begin{tabular}{lllll}
\hline & EL group $(n=10)$ & E group $(n=10)$ & L group $(n=10)$ & $2(20 \%)^{*}$ \\
\hline Rate of ROSC, $\mathrm{n}(\%)$ & $10(100 \%)^{\# \#}$ & $8(80 \%)$ & $2(20 \%)$ & $<0.001$ \\
Survival rate, $\mathrm{n}(\%)$ & $10(100 \%)^{* \# \#}$ & $4(40 \%)$ & $165 \pm 19$ & 0.001 \\
Time to CA, s & $167 \pm 28$ & $167 \pm 26$ & $99 \pm 19^{* *}$ & 0.986 \\
Time to return of pulse, s & $39 \pm 7^{\# \#}$ & $44 \pm 10$ & $277 \pm 10^{* *}$ & $<0.001$ \\
Time to ROSC, s & $47 \pm 7^{* * \#}$ & $81 \pm 22$ & 0.001 \\
\hline
\end{tabular}

Normal distributed data are given as mean $\pm \mathrm{SD}$. The $\mathrm{EL}, \mathrm{E}$ and $\mathrm{L}$ groups displayed differences in the rate of $\mathrm{ROSC}(P<0.001 ; \mathrm{EL}$ vs. $\mathrm{E}, P=0.474 ; \mathrm{EL}$ vs. $\mathrm{L}, P=0.001 ;$ $E$ vs. $\mathrm{L}, P=0.023)$. The $\mathrm{EL}, \mathrm{E}$ and $\mathrm{L}$ groups displayed difference in rates of survival $(P=0.001 ; \mathrm{EL}$ vs. $\mathrm{E}, P=0.011 ; \mathrm{EL}$ vs. $\mathrm{L}, P=0.001 ; \mathrm{E}$ vs. $\mathrm{L}, P=0.628)$. There were no differences among the three groups in the time to $C A(P>0.05)$. The $E \mathrm{~L}, \mathrm{E}$ and $\mathrm{L}$ groups displayed differences in the time to return of pulse $(P<0.001$; $\mathrm{EL}$ vs. $\mathrm{E}$, $P=0.354$; EL vs. $L, P<0.001$; E vs. L, $P<0.001)$. The EL, E, and $\mathrm{L}$ groups displayed differences in the time to $\mathrm{ROSC}(P=0.001 ; \mathrm{EL}$ vs. $\mathrm{E}, P=0.008 ; \mathrm{EL}$ vs. $\mathrm{L}, P=0.021 ;$ E vs. $L, P<0.001),{ }^{*} P<0.05,{ }^{* *} P<0.01$, versus group $E_{;}^{\#} P<0.05,{ }^{\# \#} P<0.01$, versus group $L$. ROSC indicates return of spontaneous circulation. $C A$ indicates cardiac arrest 

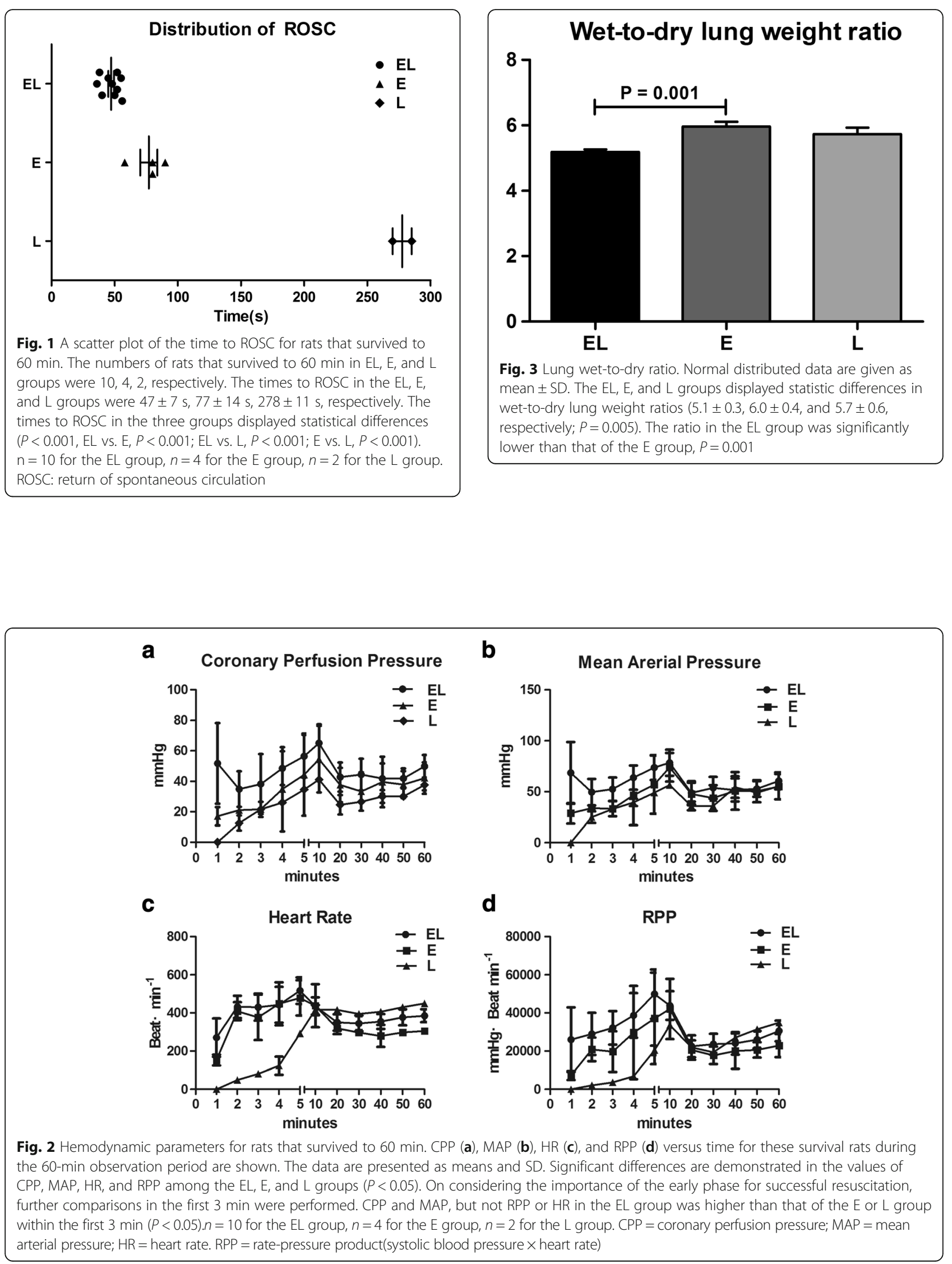


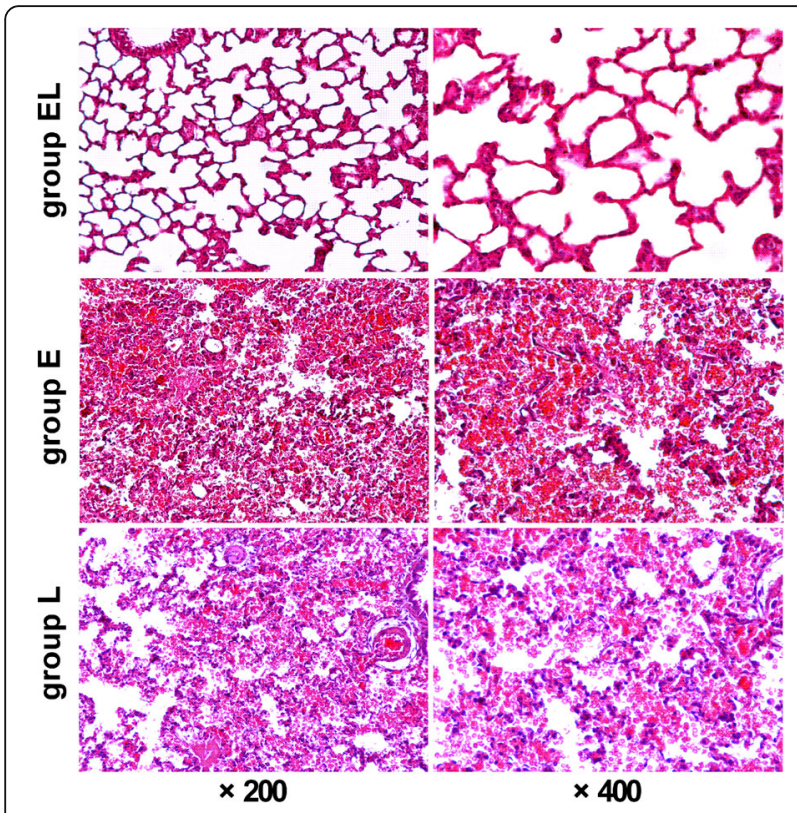

Fig. 4 The samples were taken from an EL, E, and $L$ group rat's right middle lobe, and the view was under light microscopy. For the rats in the EL group, the alveolar structures are normal and there is no leukocyte or erythrocyte accumulation seen in the alveoli. In the $E$ group, most of the alveoli are destroyed, and their structures are significantly altered, with numerous erythrocytes evident accompanying the damaged alveolar framework. In the $\mathrm{L}$ group, some alveoli are identified, and there are numerous erythrocytes observed in the alveoli. The $E L, E$, and $L$ groups displayed statistical differences in the rate of damaged alveoli $(0.15 \pm 0.07,0.74 \pm 0.08$, and $0.53 \pm 0.31$, respectively; $P=0.002$ ). The rate of damaged alveoli in the EL group was significantly lower than that in the E group, $P<0.001$. Magnification: 200x (left panel), 400× (right panel)

atrium [11]. Epinephrine can constrict the peripheral blood vessels and increase aortic pressure. Concomitant therapy with epinephrine and levosimendan has a synergistic effect on elevating CPP. In our study, CPP in the epinephrine supplemented with levosimendan group increased more significantly than the other two groups within $3 \mathrm{~min}$, with an average $\mathrm{CPP}>20 \mathrm{mmHg}$. It may be this synergistic effect that leads to all rats exhibiting ROSC in the EL group, suggesting that maximizing CPP quickly and efficiently is the key component to improving CPR outcomes. Levosimendan alone can not enhance CPP during CPR because of its peripheral vasodilatory effect. The result of our study was that CPP and the resuscitation rate of the levosimendan group was the lowest among the three groups.

Myocardium contraction weakened when heart failure, correlated with the decrease in extracellular $\mathrm{Ca}^{2+}$ inflow, reduced the sarcoplasmic reticulum uptake of release of $\mathrm{Ca}^{2+}$ and hindered the binding between troponin and $\mathrm{Ca}^{2+}$. Levosimendan is a selective systolic calcium sensitizer mainly used clinically for the treatment of acute heart failure. When sudden CA occurs, synthesis of ATP is blocked and myocardial cell cannot pump redundant $\mathrm{Ca}^{2+}$ to the extracellular space, thereby inhibiting excitation contraction coupling. Myocardial cytoclasis then occurs due to an overload of calcium. If CPR is implemented immediately, myocardial perfusion would maintain calcium ion at 25 to $30 \%$ of normal levels. Epinephrine is added at the same time to constrict the blood vessels to enhance CPP. In addition, levosimendan has a direct vasodilatory effect on coronary arteries and enhances coronary blood flow [23, 24]. In this case, myocardial cells decompose glucose to obtain the minimal requirement of ATP to continue the mechanism of calcium-triggered calcium release. If so, levosimendan could exert the function of sensitization to strengthen the contractility of myocardial cells.

Krishnamoorthy et al. [6] reported that intravenous injection of epinephrine in healthy adult rats induced rapid deterioration of pulmonary oxygen exchange, but the effects were blunted by $\alpha$-adrenergic receptor blockade. Lindberg et al. [25] showed that epinephrine caused peripheral vasoconstriction through excitation of alpha receptors, which increased cardiac afterload, and could further increase left atrial and pulmonary vein pressure. In addition, the Morelli study suggested that levosimendan could expand the peripheral vascular bed and decrease the cardiac afterload in patients who suffer from acute respiratory distress syndrome [26]. Bracken et al. [27] also demonstrated that levosimendan reduced the

Table 3 Arterial Blood Gas Parameters at 60 min

\begin{tabular}{lllll}
\hline & EL group $(n=10)$ & E group $(n=10)$ & L group $(n=10)$ & $7.14 \pm 0.18$ \\
\hline $\mathrm{PH}$ & $7.32 \pm 0.02^{* \#}$ & $7.06 \pm 0.24$ & $93 \pm 85$ & 0.01 \\
$\mathrm{PaO}_{2}, \mathrm{mmHg}$ & $173 \pm 33^{* *}$ & $91 \pm 27$ & $19.0 \pm 4.0$ & 0.008 \\
$\mathrm{HCO}_{3}^{-}, \mathrm{mmol} / \mathrm{L}$ & $21.6 \pm 1.6^{* *}$ & $14.3 \pm 5.1$ & $-10.1 \pm 4.5$ & 0.001 \\
$\mathrm{BE}, \mathrm{mmol} / \mathrm{L}$ & $-4.6 \pm 1.7^{* * \#}$ & $-16.5 \pm 8.3$ & $8.7 \pm 4.0$ & 0.001 \\
Lactate, $\mathrm{mmol} / \mathrm{L}$ & $1.1 \pm 0.5^{* \# \#}$ & $8.0 \pm 6.2$ & 0.002 \\
\hline
\end{tabular}

Normal distributed data are given as mean $\pm \mathrm{SD}$. The $\mathrm{EL}, \mathrm{E}$ and $\mathrm{L}$ groups demonstrated differences in blood gas values. The $\mathrm{pH}, \mathrm{PaO}_{2}, \mathrm{HCO}_{3}^{-}$and $\mathrm{BE}$ values in the EL group were higher than that in the $\mathrm{E}$ group ( $\mathrm{PH}$ : $\mathrm{EL}$ vs. $\mathrm{E}, P=0.021 ; \mathrm{PaO}_{2}$ : $\mathrm{EL}$ vs. $\mathrm{E}, P<0.001 ; \mathrm{HCO}_{3}^{-}$: $\mathrm{EL}$ vs. $\mathrm{E}, P=0.004 ; \mathrm{BE}$ : $\mathrm{EL}$ vs. $\mathrm{E}, P=0.004$ ). The $\mathrm{PH}$ and $\mathrm{BE}$ values in the $E L$ group were higher than that in the $L$ group ( $P H$ : $E L$ vs. $L, P=0.024$; $B E$ : EL vs. $L, P=0.01$ ). The blood lactate value in the EL group were lower than that of the $\mathrm{E}$ or $\mathrm{L}$ group (EL vs. $\mathrm{E}, P=0.018$; $\mathrm{EL}$ vs. $\mathrm{L}, P=0.001)$. There were no differences between $\mathrm{EL}$ group and $\mathrm{L}$ group in the $\mathrm{PaO} \mathrm{O}_{2}$ and $\mathrm{HCO}_{3}^{-}$values $(P>0.05)$. ${ }^{*} P<0.05,{ }^{* *} P<0.01$, versus group $E ;{ }^{\#} P<0.05,{ }^{\# \#} P<0.01$, versus group $L$. BE indicates base excess 
pressure of cat pulmonary arteries. In the present experiment, rats receiving epinephrine supplemented with levosimendan showed less lung injury and acidosis after resuscitation. This result suggests that the vasodilatory effects of levosimendan could partly offset the epinephrine-induced side effects. The complementary effect of these two medications could xhave possible beneficial CPR outcomes CPR outcomes.

Many $\alpha$-agonist agents have been shown to increase CPP. However, no placebo-controlled study has shown that the use of any vasoconstrictor during CA can increase survival rates [14]. Kelm et al. [12] reported that levosimendan combined with vasopressin administration during CPR resulted in increased cerebral blood flow and improved neurological outcomes. However, their study failed to demonstrate that the combination of the above two medications can facilitate ROSC in a rat model of asphyctic CA. Kosmidou et al. [13] showed that $12 \mu \mathrm{g} / \mathrm{kg}$ levosimendan combined with $20 \mu \mathrm{g} / \mathrm{kg}$ epinephrine only improved 24-h neurological outcomes in a swine model of asphyctic CA. However, Koudouna et al. [14] reported that the same dose of levosimendan combined with epinephrine significantly improved CPP and initial resuscitation success in a swine model of ventricular fibrillation CA. In our study, $10 \mu \mathrm{g} / \mathrm{kg}$ epinephrine combined with $12 \mu \mathrm{g} / \mathrm{kg}$ levosimendan significantly improved survival rates in a rat model of asphyctic CA. The difference of species and dosage may result in encouraging results our study has observed. Nevertheless, the ideal dosage of each medication to produce the best effect is still not clear, which requires additional studies on the dosage-response relationship of epinephrine and levosimendan on CPR.

It should be recognized that this study has limitations. Our study focused exclusively on short-term survival results and does not address neurological outcomes and long-term survival outcomes, which are the end point of cardiopulmonary cerebral resuscitation in clinical practice. We will explore these parameters in future experiments.

\section{Conclusion}

As a calcium-sensitizer agent, levosimendan improved initial resuscitation outcomes in asphyxia-induced CA when administered with epinephrine during CPR. These effects may contribute to increased coronary perfusion flow and reduced lung injury and acidosis. Our study has suggested that levosimendan can be selected as a promising alternative supplement agent to epinephrine during CPR for asphyxia-induced CA.

\section{Additional file}

Additional file 1: All data generated or analysed during this study. (ZIP $67 \mathrm{~kb}$ )

\section{Abbreviations}

BE: Base excess; CA: Cardiac arrest; CPP: Coronary perfusion pressure; CPR: Cardiopulmonary resuscitation; HR: Heart rate; MAP: Mean arterial pressure; ROSC: Return of spontaneous circulation; RPP: Rate-pressure product

\section{Acknowledgements}

We would like to thank Zhengqian Li from Peking University Third Hospital of China for revising the manuscript and Corey Astrom of the University of Florida for her editorial assistance.

\section{Funding}

This work was supported by the Natural Science Foundation of Zhejiang province, China (no. Y13H090050). This funding was used for the design of the study and the collection of data.

\section{Availability of data and materials}

All data generated or analysed during this study are included in this published article (Additional file 1).

\section{Authors' contributions}

BW: Contribution: Design the study, conduct the study, analyse the data, and write the manuscript. YP: Contribution: Design the study and write the manuscript. SZ: Contribution: Conduct the study and write the manuscript. NB: Contribution: Conduct the study and study data collection. LP: Contribution: Conduct the study. JD: Contribution: Conduct the study. XX: Contribution: Design the study, analyse the data, and write the manuscript QW: Contribution: Write the manuscript and critical manuscript review, writing and preparation. All authors read and approved the final manuscript.

\section{Competing interests}

The authors declare that they have no competing interests.

\section{Consent for publication}

Not applicable.

\section{Ethics approval}

This experiment was approved by the Ethics Committee of the Wenzhou Medical University (Wenzhou, Zhejiang, China) in accordance with the Guideline for the Care and Use of Laboratory Animals.

\section{Author details}

'Department of Anesthesiology, The First Affiliated Hospital, Wenzhou Medical University, Wenzhou City, Zhejiang Province, China. ${ }^{2}$ Department of Anesthesiology, College of Medicine, University of Florida Shands Hospital, Gainesville, FL, USA. ${ }^{3}$ The First Affiliated Hospital, Wenzhou Medical University, South Baixiang Rd, Wenzhou City, Zhejiang Province 325000, China.

Received: 21 April 2016 Accepted: 23 January 2017

Published online: 02 February 2017

\section{References}

1. Meyer L, Stubbs B, Fahrenbruch C, et al. Incidence, causes, and survival trends from cardiovascular-related sudden cardiac arrest in children and young adults 0 to 35 years of age: a 30-year review. Circulation. 2012;126: 1363-72.

2. Xanthos T, Pantazopoulos I, Demestiha T, Stroumpoulis K. Epinephrine in ventricular fibrillation: friend or foe? A review for the emergency nurse. J Emerg Nurs. 2011;37:408-12.

3. Callaway CW. Epinephrine for cardiac arrest. Curr Opin Cardiol. 2013;28:36-42.

4. Ditchey RV, Lindenfeld J. Failure of epinephrine to improve the balance between myocardial oxygen supply and demand during closed-chest resuscitation in dogs. Circulation. 1988;78:382-9.

5. Tang W, Weil MH, Sun S, Noc M, Yang L, Gazmuri RJ. Epinephrine increases the severity of post resuscitation myocardial dysfunction. Circulation. 1995; 92:3089-93.

6. Krishnamoorthy $\mathrm{V}$, Hiller DB, Ripper $\mathrm{R}$, et al. Epinephrine induces rapid deterioration in pulmonary oxygen exchange in intact, anesthetized rats: a flow and pulmonary capillary pressure-dependent phenomenon. Anesthesiology. 2012;117:745-54. 
7. Neumar RW, Shuster M, Callaway CW, et al. Part 1: executive summary: 2015 American Heart Association guidelines update for cardiopulmonary resuscitation and emergency cardiovascular care. Circulation. 2015;132 S315-67.

8. Jamali IN, Kersten JR, Pagel PS, Hettrick DA, Warltier DC. Intracoronary levosimendan enhances contractile function of stunned myocardium. Anesth Analg. 1997;85:23-9.

9. Ukkonen H, Saraste M, Akkila J, et al. Myocardial efficiency during levosimendan infusion in congestive heart failure. Clin Pharmacol Ther. 2000;68:522-31.

10. Figgit DP, Gillies PS, Goa KL. Levosimendan. Drugs. 2001;61:613-27.

11. Tassani P, Schad H, Heimisch W, et al. Effect of the calciumsensitizer levosimendan on the performance of ischaemicmyocardium in anaesthetised pigs. Cardiovascular Drugs Ther. 2002;16:435-41.

12. Kelm RF, Wagenfuhrer J, Bauer H, Schmidtmann I, Engelhard K, Noppens RR. Effects of levosimendan on hemodynamics, local cerebral blood flow, neuronal injury, and neuro inflammation after asphyctic cardiac arrest in rats. Crit Care Med. 2014;42:e410-9.

13. Kosmidou ML, Xanthos T, Chalkias A, et al. Levosimendan improves neurological outcome in a swine model of asphyxial cardiac arrest. Heart Lung Circ. 2015;24:925-31.

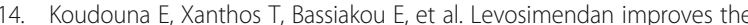
initial outcome of cardiopulmonary resuscitation in a swine model of cardiac arrest. Acta Anaesthesiol Scand. 2007:51:1123-9.

15. Jin Z, Xia Y, Xia F, et al. Epinephrine administration in lipid-based resuscitation in a rat model of bupivacaine-induced cardiac arrest: optimal timing. Reg Anesth Pain Med. 2015;40:223-31.

16. Li Z, Xia Y, Dong X, et al. Lipid resuscitation of bupivacaine toxicity: longchain triglyceride emulsion provides benefits over long- and medium-chain triglyceride emulsion. Anesthesiology. 2011;115:1219-28.

17. Paradis NA, Martin GB, Rivers EP, et al. Coronary perfusion pressure and the return of spontaneous circulation in human cardiopulmonary resuscitation. JAMA. 1990;263:1106-13.

18. McCaul CL, McNamara PJ, Engelberts D, et al. Epinephrine increases mortality after brief asphyxial cardiac arrest in an in vivo rat model. Anesth Analg. 2006;102:542-8

19. Di Gregorio G, Schwartz D, Ripper R, et al. Lipid emulsion is superior to vasopressin in a rodent model of resuscitation from toxin-induced cardiac arrest. Crit Care Med. 2009;37:993-9.

20. Murata T, Nakazawa H, Mori I, Ohta Y, Yamabayashi H. Reperfusion after a two-hour period of pulmonary artery occlusion causes pulmonary necrosis. Am Rev Respir Dis. 1992;146:1048-53.

21. Reynolds JC, Salcido DD, Menegazzi JJ. Coronary perfusion pressure and return of spontaneous circulation after prolonged cardiac arrest. Prehosp Emerg Care. 2010;14:78-84.

22. Friess SH, Sutton RM, Bhalala U, et al. Hemodynamic directed cardiopulmonary resuscitation improves short-term survival from ventricular fibrillation cardiac arrest. Crit Care Med. 2013:41:2698-704.

23. Gruhn N, Nielsen-Kudsk JE, Theilgaard S, Bang L, Olesen SP, Aldershvile J. Coronary vasorelaxant effect of levosimendan, a new inodilator with calcium-sensitizing properties. J Cardiovasc Pharmacol. 1998;31:741-9.

24. Kivikko M, Lehtonen L. Levosimendan: a new inodilatory drug for the treatment of decompensated heart failure. Curr Pharm Des. 2005;11:435-55.

25. Lindberg L, Liao Q, Steen S. The effects of epinephrine/norepinephrine on end-tidal carbon dioxide concentration, coronary perfusion pressure and pulmonary arterial blood flow during cardiopulmonary resuscitation. Resuscitation. 2000:43:129-40

26. Morelli A, Teboul JL, Maggiore SM, et al. Effects of levosimendan on right ventricular afterload in patients with acute respiratory distress syndrome: a pilot study. Crit Care Med. 2006;34:2287-93.

27. De Witt $B J$, Ibrahim IN, Bayer $E$, et al. Ananalysis of responses to levosimendan in the pulmonary vascular bed of the cat. Anesth Analg 2002;94:1427-33.

\section{Submit your next manuscript to BioMed Central and we will help you at every step:}

- We accept pre-submission inquiries

- Our selector tool helps you to find the most relevant journal

- We provide round the clock customer support

- Convenient online submission

- Thorough peer review

- Inclusion in PubMed and all major indexing services

- Maximum visibility for your research

Submit your manuscript at www.biomedcentral.com/submit

CBiomed Central 